\title{
Exchange-Biased $\mathrm{NiFe}_{2} \mathrm{O}_{4} / \mathrm{NiO}$ Nanocomposites Derived from $\mathrm{NiFe-Layered} \mathrm{Double} \mathrm{Hydroxides} \mathrm{as} \mathrm{a} \mathrm{Single} \mathrm{Precursor}$
}

\author{
Xiaofei Zhao, Sailong Xu, Lianying Wang, Xue Duan, and Fazhi Zhang ( $\triangle$ ) \\ State Key Laboratory of Chemical Resource Engineering, Beijing University of Chemical Technology, Beijing 100029, China \\ Received: 5 November 2009 / Revised: 21 January 2010 / Accepted: 22 January 2010 \\ (C) The Author(s) 2010. This article is published with open access at Springerlink.com
}

\begin{abstract}
$\mathrm{NiFe}_{2} \mathrm{O}_{4}$ nanoparticles $(<10 \mathrm{~nm})$ embedded in a $\mathrm{NiO}$ matrix have been fabricated by calcining the corresponding $\mathrm{Ni}^{\mathrm{II}} \mathrm{Fe}^{\mathrm{II}}$-layered double hydroxide $(\mathrm{LDH})$ precursors at high temperature $\left(500{ }^{\circ} \mathrm{C}\right)$. Compared with the $\mathrm{NiFe}_{2} \mathrm{O}_{4} / \mathrm{NiO}$ nanocomposite obtained by calcination of a precursor prepared by a traditional chemical coprecipitation method, those derived from NiFe-LDH precursors show much higher blocking temperatures $\left(T_{\mathrm{B}}\right)(\sim 380 \mathrm{~K})$. The enhanced magnetic stability can be ascribed to the much stronger interfacial interaction between $\mathrm{NiFe}_{2} \mathrm{O}_{4}$ and $\mathrm{NiO}$ phases due to the topotactic nature of the transformation of the $\mathrm{LDH}$ precursor to the $\mathrm{NiFe}_{2} \mathrm{O}_{4} / \mathrm{NiO}$ composite material. Through tuning the $\mathrm{Ni}{ }^{\mathrm{II}} / \mathrm{Fe}^{\mathrm{III}}$ molar ratio of the $\mathrm{NiFe}-\mathrm{LDH}$ precursor, the $\mathrm{NiFe}_{2} \mathrm{O}_{4}$ concentration can be precisely controlled, and the $T_{\mathrm{B}}$ value as well as the magnetic properties of the final material can also be regulated. This work represents a successful example of the fabrication of ferro(ferri)magnetic (FM)/antiferrimagnetic (AFM) systems with high magnetic stability from LDH precursors. This method is general and may be readily extended to other FM/AFM systems due to the wide range of available LDH precursors.
\end{abstract}

\section{KEYWORDS}

Layered double hydroxide, topotactic mechanism, interfacial interaction, exchange bias, magnetic stability

\section{Introduction}

Layered double hydroxides (LDHs), also known as hydrotalcite-like materials, are an important class of layered materials and have the general formula $\left[\mathrm{M}_{1-y}^{\mathrm{II}} \mathrm{M}^{\mathrm{III}}{ }_{y}(\mathrm{OH})_{2}\right]^{y+}\left(\mathrm{A}^{n-}\right)_{y / n} \cdot m \mathrm{H}_{2} \mathrm{O}$, where $\mathrm{M}^{\mathrm{II}}$ and $\mathrm{M}^{\mathrm{III}}$ are di- and trivalent metal cations, respectively, $\mathrm{A}^{n-}$ denotes an organic or inorganic anion with negative charge $n$, and $y\left(=\left[\mathrm{M}^{\mathbb{I I}}\right] /\left(\left[\mathrm{M}^{\mathrm{II}}\right]+\left[\mathrm{M}^{\mathrm{II}}\right]\right)\right)$ is the stoichiometric coefficient. LDHs have a wide range of applications in many fields, e.g., as catalysts or catalyst precursors, ion exchangers, adsorbents for environmental contaminants, and substrates for the immobilization of biological material [1-14]. Thermal decomposition of the $\mathrm{LDH}$ at high temperature leads to the formation of mixed metal oxide (MMO) materials composed of spinel-like $\left(\mathrm{M}^{\mathrm{II}} \mathrm{M}_{2}^{\mathrm{II}} \mathrm{O}_{4}\right)$ phases and other metal oxide phases $\left(\mathrm{M}^{\mathrm{II}} \mathrm{O}\right)$ and previous studies have shown that such materials can be used as catalysts and catalyst supports, sensors, and Li-ion battery electrodes [15-17]. In particular, thermal treatment of LDH precursors containing $\mathrm{Fe}^{\mathrm{II}}$ in the layers leads to the formation of spinel ferrite materials with excellent magnetic properties [18].

It has been shown that the metal cations within the LDH layers are uniformly ordered on an atomic

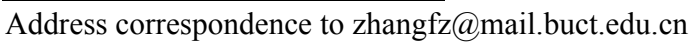


level [19], and the mechanism of the transformation from the LDH precursor to the final composites has been investigated in detail [20-22]. The structure of the $\mathrm{LDH}$ precursor belongs to the hexagonal group, and the cations on the $(00 l)$ facets are arranged in an ordered "hexagon" formation. The cations on the (111) facets of $\mathrm{M}^{\mathrm{II}} \mathrm{O}$ and $\mathrm{M}^{\mathrm{II}} \mathrm{M}^{\mathrm{III}}{ }_{2} \mathrm{O}_{4}$ phases, both of which have face-centered cubic lattices, are also arranged in an ordered "hexagon" formation, just as in the LDH precursor (as shown in Fig. 1). Moreover, the distance between the metal cations on the (111) facets of $\mathrm{M}^{\mathrm{I}} \mathrm{O}$ and $\mathrm{M}^{\mathrm{II}} \mathrm{M}_{2}^{\mathrm{II}} \mathrm{O}_{4}$ phases are very similar to that on the (00l) facets of LDHs. Therefore, as a result of the
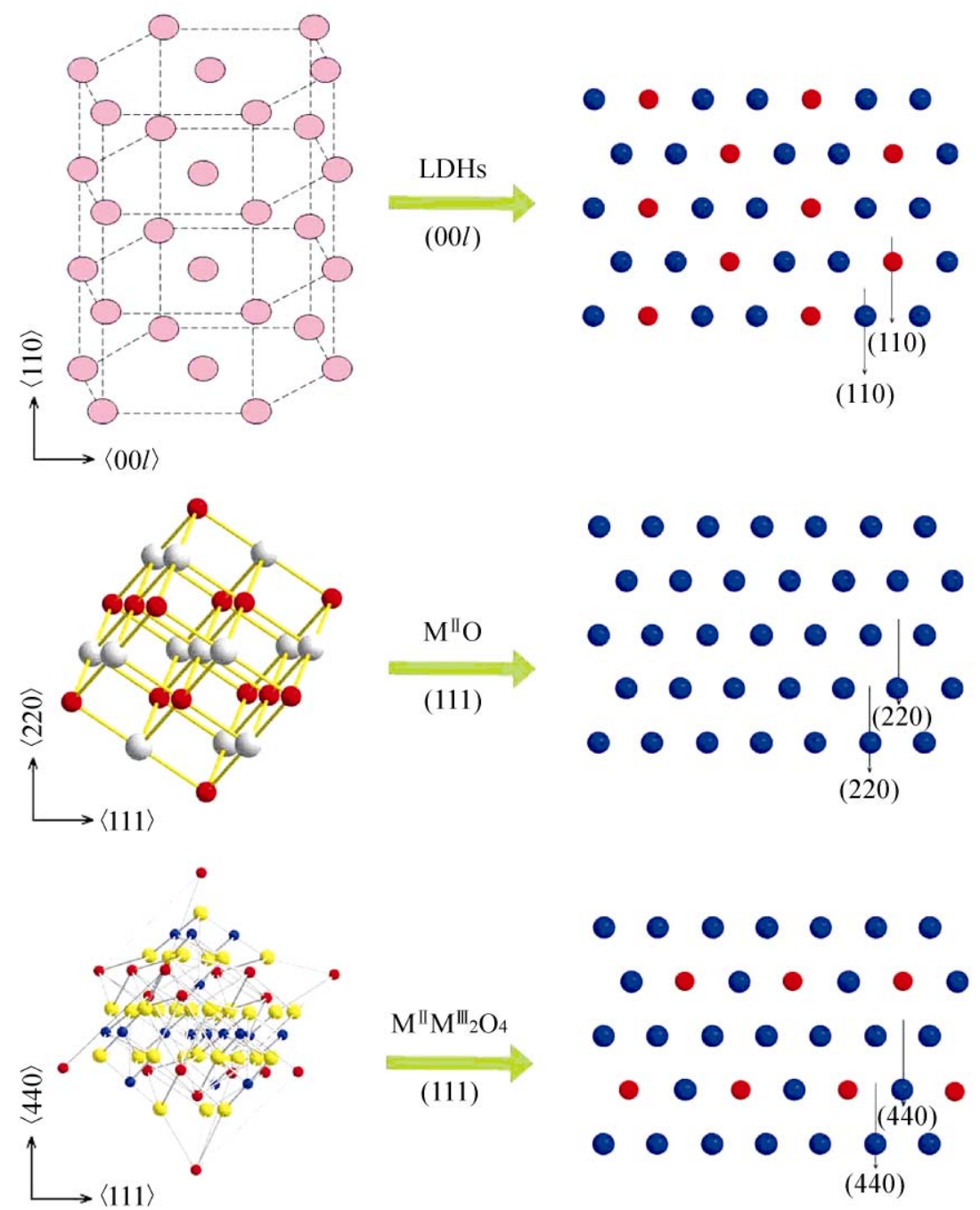

$\mathrm{M}^{\mathrm{III}}$, such as $\mathrm{Al}^{3+}, \mathrm{Fe}^{3+}$, etc.
$\mathrm{M}^{\mathrm{II}}$, such as $\mathrm{Ni}^{2+}, \mathrm{Mg}^{2+}$, etc.

Figure 1 Structures of the LDH precursor, $\mathrm{M}^{\mathrm{II}} \mathrm{O}$ and $\mathrm{M}^{\mathrm{II}} \mathrm{M}_{2}^{\mathrm{II}} \mathrm{O}_{4}$ and their corresponding $(00 l),(111)$, and (111) planes closely related symmetry of the $(00 l)$ facets of the $\mathrm{LDH}$ precursors and the (111) facets of the $\mathrm{M}^{\mathrm{II}} \mathrm{O}$ and $\mathrm{M}^{\mathrm{II}} \mathrm{M}^{\mathrm{III}}{ }_{2} \mathrm{O}_{4}$ phases, the transformation occurring during thermal decomposition is a topotactic process. Meanwhile, since the value of the stoichiometric coefficient $y$ for LDHs is typically in the range $0.25-0.33$ (i.e., the $\mathrm{M}^{\mathrm{II}}: \mathrm{M}^{\mathrm{II}}$ molar ratios are between 3:1 and 2:1), the $\mathrm{M}^{\mathrm{II}}$ $\mathrm{M}_{2}^{\mathrm{II}} \mathrm{O}_{4}$ phase is embedded in a matrix of excess $\mathrm{M}^{\mathrm{II}} \mathrm{O}$. Moreover, owing to the cations within the layers of the LDH precursors being uniformly ordered on an atomic level, the two phases in the final composites are uniformly interdispersed.

Interest in nanosized ferro/ferrimagnetic (FM) particles has increased greatly in recent years because of their wide range of applications in various fields [23-27]. In the case of information storage, achieving ultrahigh densities requires the preparation of materials with very small particle size. This however lowers the anisotropy energy, which maintains the magnetic moments along certain directions, and it becomes comparable to the thermal energy at a relatively low temperatures, well below room temperature. At this temperature, known as the blocking temperature $\left(T_{\mathrm{B}}\right)$, the nanoparticles lose their magnetic order and become superparamagnetic. If nanosized FM particles are to have actual practical applications in areas such as magnetic recording, it is essential to find ways of raising the value of $T_{B}$ to room temperature and above. According to recent studies, exchange bias effects in composite systems have been discovered as a way to overcome the "superparamagnetic limit" of FM nanoparticles [28-30], since it has been demonstrated that exchange coupling between the FM and AFM spin systems 
induces an anisotropy in the FM materials which can leads to substantial increases in $T_{B}$. Many of the studied exchange-biased systems, which are fabricated by the chemically modifying the surface of a preformed FM core, are composed of homogenous transition metal ferromagnetic cores and a corresponding passive shell, such as $\mathrm{Co} / \mathrm{CoO}$ [31], $\mathrm{Ni} / \mathrm{NiO}$ [32], or oxides with different oxidation states as in $\mathrm{Fe}_{3} \mathrm{O}_{4} / \mathrm{FeO}$ [33] and $\mathrm{Mn}_{3} \mathrm{O}_{4} / \mathrm{MnO}$ [34]. $\mathrm{Co} / \mathrm{NiO}$ or $\mathrm{Co} / \mathrm{FeS}$ core/shell nanostructures have also been fabricated using a ball milling method [35].

The exchange bias effect has also been used to improve the magnetic stability of ferrite nanoparticles and various different heterogeneous FM spinel ferrite/AFM oxide systems with different structures have been developed by a variety of chemical methods. For instance, spinel ferrite/MnO core/shell nanoparticles can be fabricated by a chemical precipitation method [36]. $\mathrm{CoFe}_{2} \mathrm{O}_{4}$ nanoparticles embedded in the $\mathrm{NiO}$ matrix have been prepared by the so-called "polyol method" [37], and $\mathrm{NiFe}_{2} \mathrm{O}_{4}$ nanoparticles embedded in a $\mathrm{NiO}$ matrix can be synthesized by a chemical coprecipitation method [38]. All these studies showed that the exchange bias interaction between the heterogeneous spinel ferrite and oxide phases could improve the magnetic stability of the ferrite nanoparticles to a certain extent. However, the above mentioned routes intrinsically lead to the sintering of the two phases and the poor quality of the interface. This has been attributed to the weak interfacial interaction between the FM spinel ferrite and the AFM oxide and a correspondingly weak exchange bias coupling between the FM spinel ferrite and the AFM oxide [31]. Therefore, the development of new preparative techniques for FM/AFM systems with highly effective exchange bias is still a target of current research.

The topotactic transformation of an LDH to MMOs suggests that a strong interfacial effect might exist between the metal oxide and spinel-like ferrite phases and could result in enhanced magnetic stability and increased $T_{\mathrm{B}}$ values. In this paper, we first fabricated $\mathrm{NiFe}-\mathrm{LDH}$ and then calcined them at high temperature to obtain nanocomposites of ferrimagnetic $\mathrm{NiFe}_{2} \mathrm{O}_{4}$ and an excess of antiferromagnetic NiO. Compared with a similar system obtained by calcination of a precursor prepared by a traditional chemical coprecipitation method (described in Ref. [38]), the $\mathrm{NiFe}_{2} \mathrm{O}_{4} / \mathrm{NiO}$ nanocomposite prepared from the $\mathrm{NiFe}-\mathrm{LDH}$ showed much higher $T_{B}$ value due to an enhanced interaction between the two phases. Furthermore, we also adjusted the $\mathrm{NiFe}_{2} \mathrm{O}_{4} / \mathrm{NiO}$ molar ratio by tailoring the $\mathrm{Ni} / \mathrm{Fe}$ molar ratio in the $\mathrm{NiFe-LDH} \mathrm{precursors,} \mathrm{and} \mathrm{investigated} \mathrm{its} \mathrm{effect} \mathrm{on}$ the magnetic properties of the final composites.

\section{Experimental}

The $\left[\mathrm{Ni}^{\mathrm{II}} \mathrm{Fe}^{\mathrm{III}}-\mathrm{NO}_{3}{ }^{-}\right] \mathrm{LDH}$ precursors with different $\mathrm{Ni}^{\mathrm{II}} / \mathrm{Fe}^{\mathrm{III}}$ molar ratios (2:1, 3:1, and 4:1) were prepared by a method involving separate nucleation and aging steps (SNAS) in a modified colloid mill developed in our laboratory [39]. The resulting suspension was removed from the colloid mill and aged at $100{ }^{\circ} \mathrm{C}$ for $48 \mathrm{~h}$. The product was washed several times with distilled water with centrifugation and was dried at $60{ }^{\circ} \mathrm{C}$ for $24 \mathrm{~h}$. $\mathrm{NiFe}_{2} \mathrm{O}_{4} / \mathrm{NiO}$ nanocomposites obtained by calcining NiFe-LDHs at 350 or $500{ }^{\circ} \mathrm{C}$ in air with a temperature ramping rate of $5^{\circ} \mathrm{C} \cdot \mathrm{min}^{-1}$ are denoted as $\mathrm{NF}-X-T$, in which $X$ denotes the molar ratio of $\mathrm{Ni}^{\mathrm{II}} / \mathrm{Fe}^{\mathrm{III}}$ in the $\mathrm{LDH}$ precursor, and $\mathrm{T}$ denotes the calcination temperature $\left({ }^{\circ} \mathrm{C}\right)$. The resulting products were slowly cooled to room temperature. For comparison, another $\mathrm{NiFe}_{2} \mathrm{O}_{4} / \mathrm{NiO}$ nanocomposite was prepared by calcination of a precursor prepared by a modified chemical coprecipitation method described in Ref. [38], and was denoted as NF-C-500. In this process, stoichiometric amounts of ferric chloride $\left(\mathrm{FeCl}_{3} \cdot 6 \mathrm{H}_{2} \mathrm{O}\right)$ and nickel chloride $\left(\mathrm{NiCl}_{2} \cdot 6 \mathrm{H}_{2} \mathrm{O}\right)$ with a $\mathrm{Ni}^{\text {II }} / \mathrm{Fe}^{\text {III }}$ molar ratio of 3:1 were first dissolved in distilled water. After that, an appropriate ammonium bicarbonate $\left(\mathrm{NH}_{4} \mathrm{HCO}_{3}\right)$ solution was added to the mixture with constant stirring. The resulting precipitate was dried at $120{ }^{\circ} \mathrm{C}$ to obtain the precursor powder. Finally, this powder was sintered under the same conditions as for the $\mathrm{LDH}$ precursors.

The nanocomposites were characterized by X-ray powder diffraction (XRD) carried out on a Shimadzu XRD-6000 diffractometer using $\mathrm{Cu} \mathrm{K} \alpha$ radiation $(40 \mathrm{kV}$, $30 \mathrm{~mA}$, and $\lambda=0.154 \mathrm{~nm}$ ) between $3^{\circ}$ and $70^{\circ}$ with a scanning rate of $5\left(^{\circ}\right) / \mathrm{min}$. Elemental analysis for metal ions was performed using a Shimadzu ICPS-75000 
inductively coupled plasma emission spectrometer (ICP-ES). Solutions were prepared by dissolving the sample in dilute hydrochloric acid (1:1). Transmission electron microscopy (TEM) was carried out with a JEOL JEM-2010 transmission electron microscope with an accelerating voltage of $200 \mathrm{kV}$. Magnetic measurements were obtained on a Quantum Design MPMS-XL Superconducting Quantum Interference Device (SQUID) magnetometer operating in the temperature range $5-400 \mathrm{~K}$.

\section{Results and discussion}

3.1 Fabrication and structural investigation of $\mathrm{NiFe}_{2} \mathrm{O}_{4} / \mathrm{NiO}$ systems obtained from a NiFe-LDH precursor and by the chemical coprecipitation method

Figure 2(a) shows the XRD pattern of a NiFe-LDH precursor, prepared from a solution with $\mathrm{Ni}^{\mathrm{II}}: \mathrm{Fe}^{\mathrm{II}}$ molar ratio of 3:1, containing interlayer nitrate anions. The XRD pattern exhibits the characteristic reflections of the LDH structure with a series of $(00 l)$ peaks at low angle and weaker non-basal reflections at higher angle [36]. Elemental analysis of the NiFe-LDH precursor gives a Ni:Fe molar ratio of 2.62 , which is similar to that in the initial synthesis mixture. Figure 2(b) shows the XRD pattern of the precursor obtained by the chemical coprecipitation method from a solution with the same $\mathrm{Ni}^{\mathrm{II}}: \mathrm{Fe}^{\mathrm{II}}$ molar ratio of 3:1. Although diffraction peaks characteristic of a material with a layered structure are apparent, the low intensity of these reflections suggests that the majority of the material obtained by the traditional chemical coprecipitation method is amorphous.

Thermal decomposition of the LDH precursor at $350{ }^{\circ} \mathrm{C}$ afforded a material giving three broad peaks in its XRD pattern, (Fig. 3(a), NF-3-350), which can be attributed to a poorly crystalline $\mathrm{NiO}$ phase. When the calcination temperature was increased to $500{ }^{\circ} \mathrm{C}$, the resulting material NF-3-500 had an XRD pattern, shown in Fig. 3(b), which corresponds to a superposition of the characteristic reflections of $\mathrm{NiFe}_{2} \mathrm{O}_{4}$ and $\mathrm{NiO}$. The mean crystallite size of the $\mathrm{NiFe}_{2} \mathrm{O}_{4}$ particles, calculated using the Scherrer formula, was about $6 \mathrm{~nm}$. It should be noted that the (111), (200), and (220) peaks of $\mathrm{NiO}$

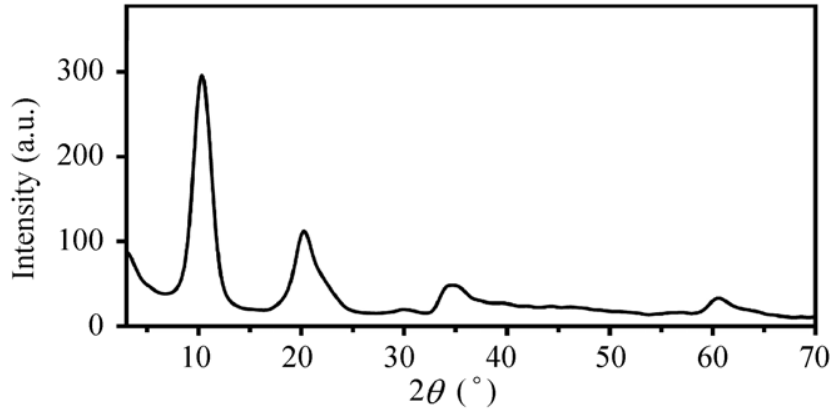

(a)

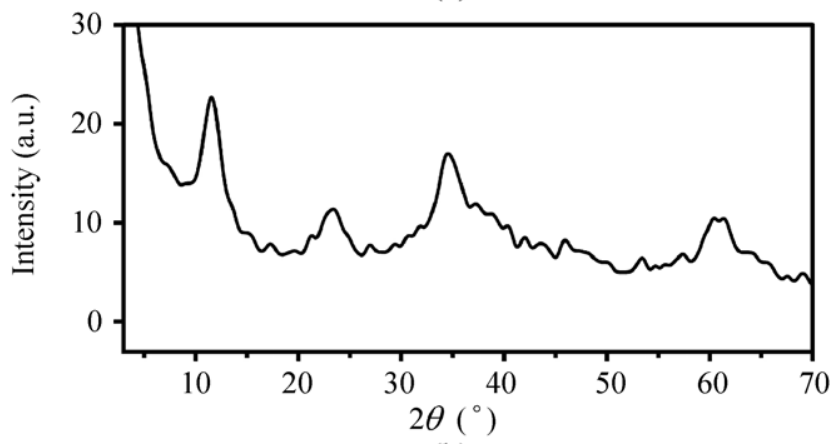

(b)

Figure 2 Powder XRD patterns for (a) the NiFe-LDH precursor, and (b) the precursor prepared by a modified chemical coprecipitation method

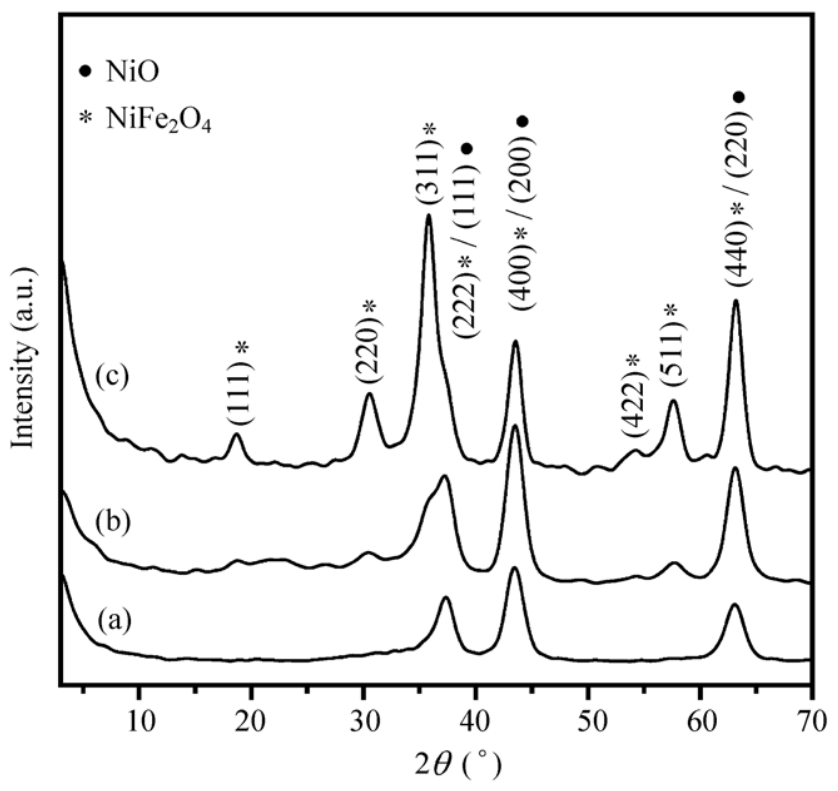

Figure 3 Powder XRD patterns of the $\mathrm{NiFe}_{2} \mathrm{O}_{4} / \mathrm{NiO}$ nanocomposites prepared by calcination of (a) the NiFe-LDH precursor at $350{ }^{\circ} \mathrm{C}(\mathrm{NF}-3-350)$, (b) the NiFe-LDH precursor at $500{ }^{\circ} \mathrm{C}$ (NF-3-500), and (c) the precursor prepared by a modified chemical coprecipitation method at $500{ }^{\circ} \mathrm{C}(\mathrm{NF}-\mathrm{C}-500)$ 
(JCPDF 47-1049) have nearly the same $2 \theta$ values as those of the (222), (400), and (440) peaks of $\mathrm{NiFe}_{2} \mathrm{O}_{4}$ (JCPDF 10-0325), and so the crystallite size of $\mathrm{NiO}$ cannot be calculated from the XRD results. Based on the $\mathrm{Ni} / \mathrm{Fe}$ molar ratio in the $\mathrm{NiFe}-\mathrm{LDH}$ precursor obtained by elemental analysis, the final molar ratio of $\mathrm{NiFe}_{2} \mathrm{O}_{4}$ to $\mathrm{NiO}$ in NF-3-500 is about 1:4.2. Similarly, for NF-C-500 obtained by calcination at $500{ }^{\circ} \mathrm{C}$ of the precursor synthesized by the chemical coprecipitation method, both the diffraction peaks of $\mathrm{NiO}$ and $\mathrm{NiFe}_{2} \mathrm{O}_{4}$ can be observed (Fig. 3(c)). Compared with those in Fig. 3(b), the intensities of the diffraction peaks of $\mathrm{NiFe}_{2} \mathrm{O}_{4}$ and $\mathrm{NiO}$ are much larger and the mean particle size of the $\mathrm{NiFe}_{2} \mathrm{O}_{4}$ (as calculated by the Scherrer formula) is about $20 \mathrm{~nm}$, which is about three times that of the material prepared using the LDH precursor method.

A typical TEM image of the NF-3-500 nanocomposite obtained by calcination of the $\mathrm{LDH}$ precursor at $500{ }^{\circ} \mathrm{C}$ showed (Fig. 4(a)) that the small nanoparticles were roughly spherical but not quite regular in shape, and seemed to be aggregated with each other such that no "isolated" particles can be observed. The estimated diameters of the spherical nanoparticles are about 5-8 nm. HRTEM (Fig. 4(b)) showed that the material was well crystallized, as evidenced by the well-defined lattice spacing in the regions selected. In Fig. 4(c), it can be observed that the particle size distribution of NF-C-500 is polydisperse, ranging from $5 \mathrm{~nm}$ to
$25 \mathrm{~nm}$, and the particles become sintered and the two phases become segregated. Such phase separation and the sintering during the calcination process are consistent with the mostly amorphous nature of the precursor formed by chemical coprecipitation. In contrast, for the NiFe-LDH precursors, a decoration model developed for NiAl-LDHs [40] suggests that the $\mathrm{NiO}$ can be viewed as "decorated" by ferrite-type patches and that this is responsible for the high thermal stability and resistance to sintering.

\subsection{Blocking temperature of $\mathrm{NiFe}_{2} \mathrm{O}_{4} / \mathrm{NiO}$ nano- composites and mechanism of the improvement of magnetic stability}

In order to investigate the $T_{B}$ of NF-3-500, the temperature-dependent magnetization curves in zerofield-cooled (ZFC) and field-cooled (FC) processes with an applied field of 100 Oe were recorded, as shown in Fig. 5(a). According to the literature, the $T_{\mathrm{B}}$ value of single-phase $\mathrm{NiFe}_{2} \mathrm{O}_{4}$ nanoparticles is much lower than room temperature when the particle size of the $\mathrm{NiFe}_{2} \mathrm{O}_{4}$ is smaller than $10 \mathrm{~nm}$. For instance, the $T_{\mathrm{B}}$ value of $\mathrm{NiFe}_{2} \mathrm{O}_{4}$ nanoparticles with a diameter of $\sim 6.4 \mathrm{~nm} \pm 1.4 \mathrm{~nm}$ has been reported to be about $95 \mathrm{~K}$ at a magnetic field of $100 \mathrm{Oe}$ [41], while a value of $60 \mathrm{~K}$ has been reported for $\mathrm{NiFe}_{2} \mathrm{O}_{4}$ with a particle size of $8.6 \mathrm{~nm}$ with the same magnetic field [42]. In contrast, in NF-3-500, at a magnetic field of 100 Oe the nanoparticles displayed a $T_{\mathrm{B}}$ of $380 \mathrm{~K}$ (Fig. 5(a)),

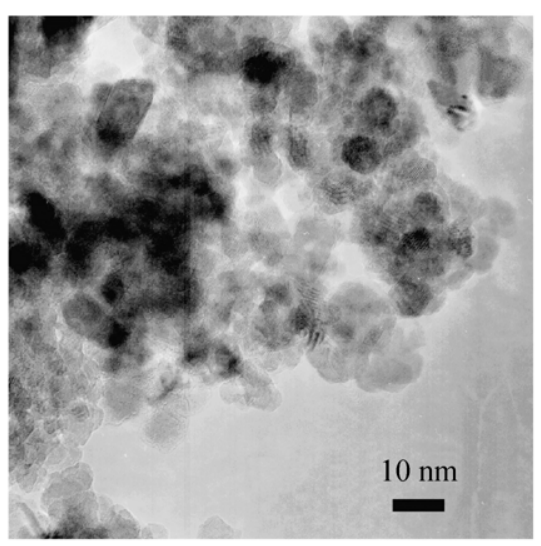

(a)

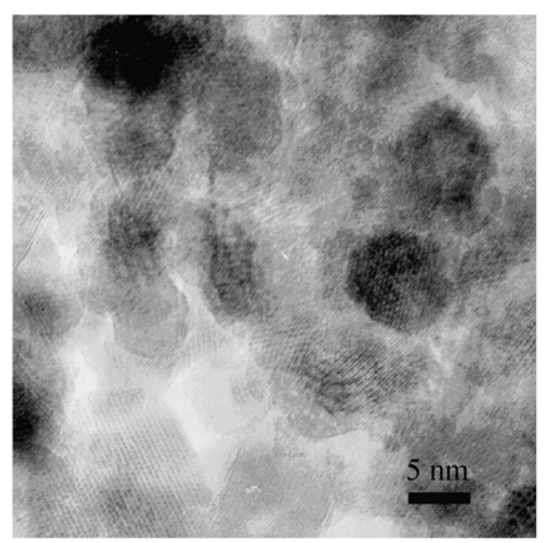

(b)

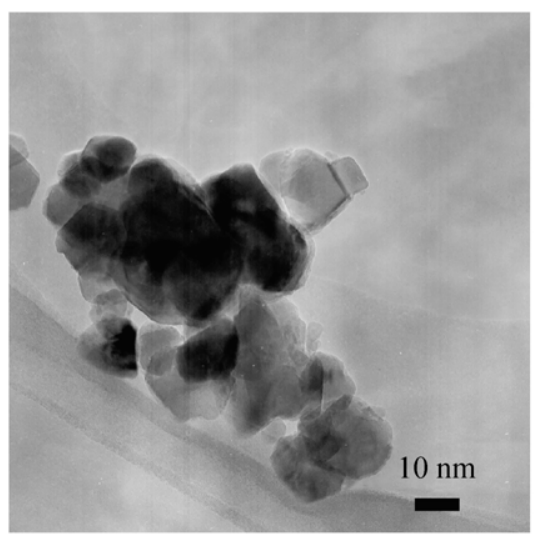

(c)

Figure 4 TEM image (a) and HRTEM image (b) of $\mathrm{NiFe}_{2} \mathrm{O}_{4} / \mathrm{NiO}$ nanocomposites prepared by calcination of the LDH precursor at $500{ }^{\circ} \mathrm{C}(\mathrm{NF}-3-500)$ and (c) TEM image of the $\mathrm{NiFe}_{2} \mathrm{O}_{4} / \mathrm{NiO}$ nanocomposite (NF-C-500) prepared by calcination at $500{ }^{\circ} \mathrm{C}$ of the precursor obtained using the chemical coprecipitation method 
much higher than room temperature. For the NF-C-500 nanocomposite, the $T_{\mathrm{B}}$ value (as shown in Fig. 5(b)) was only $280 \mathrm{~K}$ - which, although higher than that for pure $\mathrm{NiFe}_{2} \mathrm{O}_{4}$, is $100 \mathrm{~K}$ lower than that of the composite material obtained by the $\mathrm{LDH}$ precursor method-in spite of the fact that the mean particle size of the $\mathrm{NiFe}_{2} \mathrm{O}_{4}$ prepared by the coprecipitation method is much larger.

Overall, the results demonstrate that for $\mathrm{NiFe}_{2} \mathrm{O}_{4} / \mathrm{NiO}$ nanocomposites synthesized from either an $\mathrm{LDH}$ precursor or precursor prepared by chemical coprecipitation, the coupling of $\mathrm{FM} \mathrm{NiFe}_{2} \mathrm{O}_{4}$ particles with the AFM NiO matrix can be a source of enhanced magnetization stability. This leads to an increase in the nanoparticle blocking temperature, with the effect being larger in the case of the material prepared by the LDH precursor route. The FM/AFM exchange coupling may be understood as follows: when the grain size of the FM particles is reduced, the energy

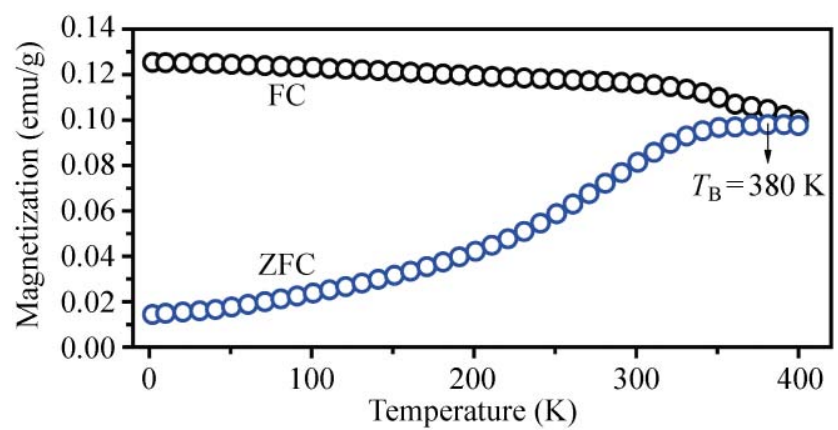

(a)

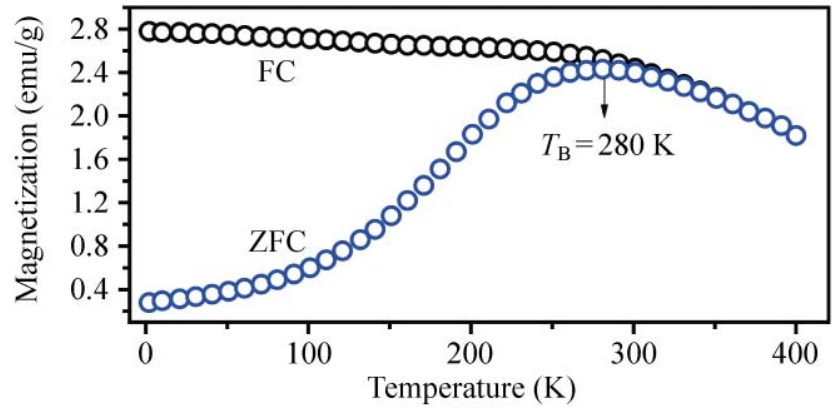

(b)

Figure 5 Temperature dependence of the magnetization of the $\mathrm{NiFe}_{2} \mathrm{O}_{4} / \mathrm{NiO}$ nanocomposite obtained by (a) calcination of the LDH precursor at $500{ }^{\circ} \mathrm{C}(\mathrm{NF}-3-500)$, and (b) obtained by calcination at $500{ }^{\circ} \mathrm{C}$ of the precursor prepared by the modified chemical coprecipitation method (NF-C-500) in ZFC and FC processes. The applied magnetic field in the FC process was $100 \mathrm{Oe}$ barrier - which is related to the magnetic stability of the FM phase, as well as the characteristic time $(\tau)$ to overcome the energy barrier-is decreased. Theoretically, $\tau$ usually is estimated in the framework of the Arrhenius-Néel statistical switching model [43]:

$$
\tau=\tau_{0} \exp \left(N \Delta E / k_{\mathrm{B}} T\right)
$$

in which $N$ is the number of atomic magnetic moments in the cluster, $T$ is the absolute temperature, $k_{\mathrm{B}}$ is the Boltzmann constant, and $\tau_{0}$ is a constant. $\Delta E$, which is the energy barrier per cluster atom, results from the magnetic lattice anisotropy and the magnetic dipole coupling. The key to increasing the magnetic stability of small FM particles is to raise the energy barrier $\Delta E$. If the FM particles, such as $\mathrm{NiFe}_{2} \mathrm{O}_{4}$, are placed in an AFM matrix, the FM moments of the $\mathrm{NiFe}_{2} \mathrm{O}_{4}$ particles create an exchange field, $\mu_{0} H_{\mathrm{ex}}$, which then acts on the interface AFM moments of the $\mathrm{NiO}$ matrix. If $H_{\mathrm{ex}}$ is considered as being formally equivalent to an external field, the coupling energy, $E^{\prime}$, is [31]:

$$
E^{\prime}=-1 / 2 \chi_{\mathrm{AF}} \mu_{0} H_{\mathrm{ex}}^{2}
$$

where $\chi_{\mathrm{AF}}$ is the susceptibility of the interface AFM moments. The energy difference $\Delta E^{\prime}$ between two FM moment directions amounts to $-1 / 2 \Delta \chi_{\mathrm{AF}} \mu_{0} H_{\mathrm{ex}}^{2}$, where $\Delta \chi_{\mathrm{AF}}$ is the associated difference in susceptibility, and may be viewed as an additional anisotropy term, acting as a source of magnetization stability of the $\mathrm{NiFe}_{2} \mathrm{O}_{4}$ nanoparticles.

On the other hand, another important factor as mentioned above, which determines the "effectiveness" of the exchange bias interaction, is the quality of the interface between the FM and AFM phases [31]. We suggest that this can account for the marked difference in the magnetic stabilities (as shown by the $T_{\mathrm{B}}$ values) of the $\mathrm{NiFe}_{2} \mathrm{O}_{4} / \mathrm{NiO}$ nanocomposites synthesized from the $\mathrm{LDH}$ precursor and by the chemical coprecipitation method. In the case of the $\mathrm{LDH}$, during the early stages of the transformation, oxide nucleation occurs on its $(00 l)$ planes where the packing of cations is the densest, giving the lowest nucleation energy, and resulting in the formation of the (111) facets of a Ni" O-like phase. Correspondingly, the $\mathrm{M}-\mathrm{OH}$ octahedra in the layers of the $\mathrm{LDH}$ are transformed into $\mathrm{M}-\mathrm{O}$ octahedra in the lattice of 
the $\mathrm{M}^{\mathrm{II}} \mathrm{O}$ phase. Most of the $\mathrm{Fe}^{\mathrm{III}}$ cations exist in the accompanying amorphous oxide phase as well being doped in the lattice of the $\mathrm{M}^{\mathrm{II}} \mathrm{O}$-like phase to form a solid solution. With increasing temperature, the $\mathrm{Fe}^{\mathrm{III}}$ cations in the amorphous phase, along with those released from the $\mathrm{Ni}^{\mathrm{II}} \mathrm{O}$ lattice, generate spinel (111) facets arising from the intermediate $\mathrm{Ni}^{\mathrm{i}} \mathrm{O}$ phase. During the whole process, the $\mathrm{O}$ atoms retain the most dense face centered packing. This topotactic transformation mechanism [20] of the decomposition of the $\mathrm{LDH}$ accounts for the close structural dependence of the resulting $\mathrm{NiFe}_{2} \mathrm{O}_{4}$ and the $\mathrm{NiO}$ matrix and the much better quality of the interface between the $\mathrm{NiO}$ matrix and the $\mathrm{NiFe}_{2} \mathrm{O}_{4}$ nanoparticles. Moreover, it can be seen from the TEM results that the sizes of the nanoparticles derived from the LDH precursor are much smaller than those obtained from the precursor prepared by the coprecipitation method and are strongly clustered with each other, giving a larger effective AFM NiO phase "thickness" around the $\mathrm{NiFe}_{2} \mathrm{O}_{4}$ nanoparticles. Furthermore, when the particles are clustered together, due to the exchange coupling effect in the $\mathrm{NiO}$ phase around different $\mathrm{NiFe}_{2} \mathrm{O}_{4}$ nanoparticles, they exert a "collective behavior" and thus have an extra effective AFM "thickness" which further increases the blocking temperature of the $\mathrm{NiFe}_{2} \mathrm{O}_{4}$ nanoparticles [44, 45].

For NF-C-500 obtained by calcination of the precursor from the chemical coprecipitation method, both the XRD and TEM results indicate that phase separation and the sintering of both the $\mathrm{NiO}$ and $\mathrm{NiFe}_{2} \mathrm{O}_{4}$ have occurred, and no cluster structures can be seen in the TEM image. Therefore, the exchange between the FM and AFM phases is much weaker due to the poor quality of the interface and the $T_{\mathrm{B}}$ value is much lower than that of the $\mathrm{NiFe}_{2} \mathrm{O}_{4} / \mathrm{NiO}$ nanocomposite derived from the $\mathrm{LDH}$ precursor.

\subsection{Fabrication of $\mathrm{NiFe}_{2} \mathrm{O}_{4} / \mathrm{NiO}$ nanocomposites with different $\mathrm{NiO}$ to $\mathrm{NiFe}_{2} \mathrm{O}_{4}$ molar ratios and investigation of their magnetic properties}

In order to investigate the impact of different $\mathrm{NiFe}_{2} \mathrm{O}_{4} / \mathrm{NiO}$ molar ratios on the $T_{\mathrm{B}}$ value and the magnetic properties of the final $\mathrm{NiFe}_{2} \mathrm{O}_{4} / \mathrm{NiO}$ nanocomposite, $\mathrm{LDH}$ precursors with different molar ratios of $\mathrm{Ni}^{\mathrm{i}} / \mathrm{Fe}^{\mathrm{III}}$ (2:1 and 4:1) were synthesized and then calcined at $500{ }^{\circ} \mathrm{C}$. The XRD patterns of the resulting materials are shown in Fig. 6. The LDH precursors with $\mathrm{Ni}^{\mathrm{II}} / \mathrm{Fe}^{\mathrm{III}}$ ratios of 2:1 and 4:1 (Figs. 6(a) and 6(b)) as well as the respective calcined samples (Figs. 7(c) and $7(\mathrm{~d})$ ) have similar XRD patterns to those in Fig. 3 for the sample with $\mathrm{Ni}^{\mathrm{II}} / \mathrm{Fe}^{\mathrm{III}}$ ratio of $3: 1$. The decomposition of the $\mathrm{LDH}$ precursor with a $\mathrm{Ni}^{\mathrm{II}} / \mathrm{Fe}^{\mathrm{II}}$ ratio of 2:1 leads to the formation of more $\mathrm{NiFe}_{2} \mathrm{O}_{4}$ nanoparticles in the final NF-2-500 material, and the diffraction peaks of the $\mathrm{NiFe}_{2} \mathrm{O}_{4}$ phase also become stronger. In contrast, in NF-4-500 obtained by calcination of the $\mathrm{LDH}$ precursors with a $\mathrm{Ni}^{\mathrm{II}} / \mathrm{Fe}^{\mathrm{III}}$ ratio of $4: 1$, the relative content of $\mathrm{NiFe}_{2} \mathrm{O}_{4}$ is much lower and the diffraction peaks of $\mathrm{NiFe}_{2} \mathrm{O}_{4}$ become shoulders or even cannot be detected.

The temperature-dependent magnetization curves in ZFC and FC modes of NF-2-500 and NF-4-500 are shown in Fig. 7. The $T_{\mathrm{B}}$ value for NF-2-500 is much lower (260 K) (Fig. 7(b)) than that for NF-3-500, whilst the $T_{\mathrm{B}}$ value for NF-4-500 is $380 \mathrm{~K}$ (Fig. 7(b)), which is very similar to that for NF-3-500. The influence of the $\mathrm{NiO}$ concentration in the final $\mathrm{NiFe}_{2} \mathrm{O}_{4} / \mathrm{NiO}$ nanocomposite systems on the exchange bias effects is illustrated schematically in Fig. 8. Unlike single-phase $\mathrm{NiFe}_{2} \mathrm{O}_{4}$ nanoparticles (Fig. 8(a)), the $\mathrm{NiFe}_{2} \mathrm{O}_{4} / \mathrm{NiO}$

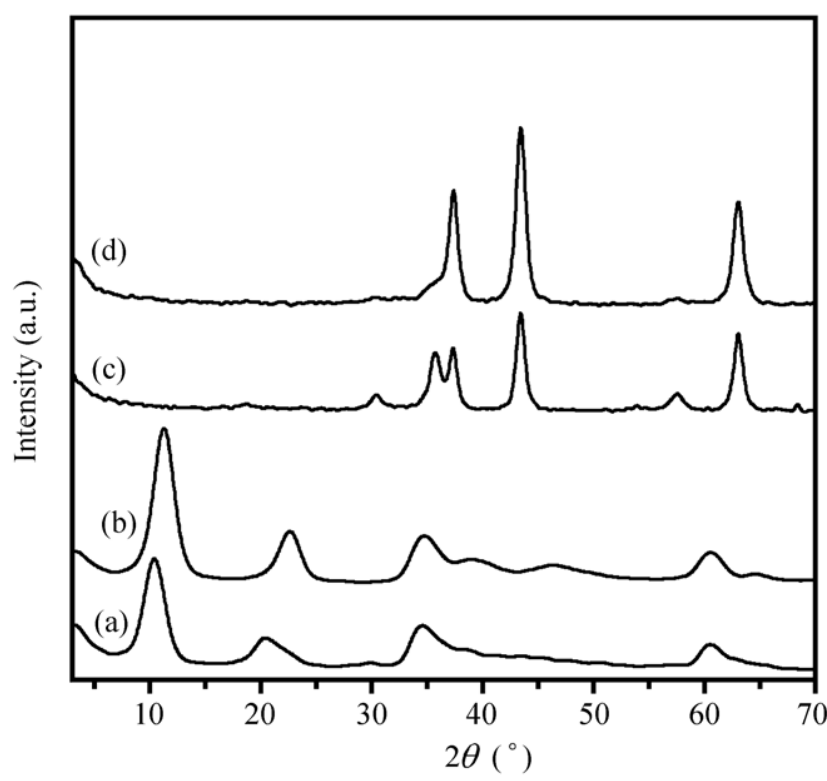

Figure 6 Powder XRD patterns of NiFe-LDH precursors with $\mathrm{Ni}^{\mathrm{II}} / \mathrm{Fe}^{\mathrm{III}}$ molar ratios of (a) 2.0 and (b) 4.0, and the corresponding $\mathrm{NiFe}_{2} \mathrm{O}_{4} / \mathrm{NiO}$ nanocomposites (c) NF-2-500 and (d) NF-4-500 obtained by calcination at $500{ }^{\circ} \mathrm{C}$ 


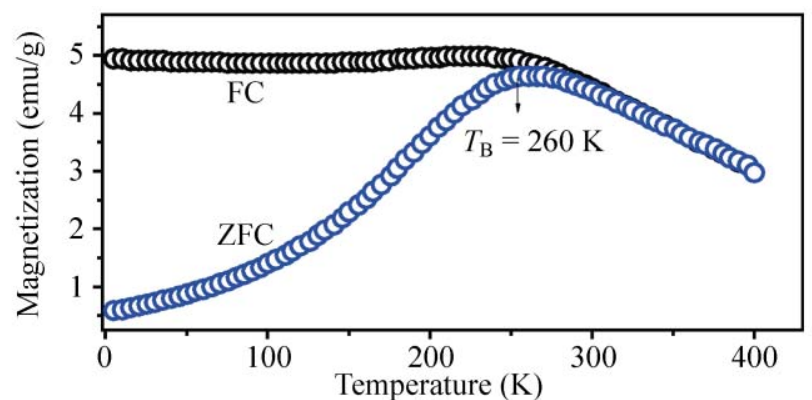

(a)

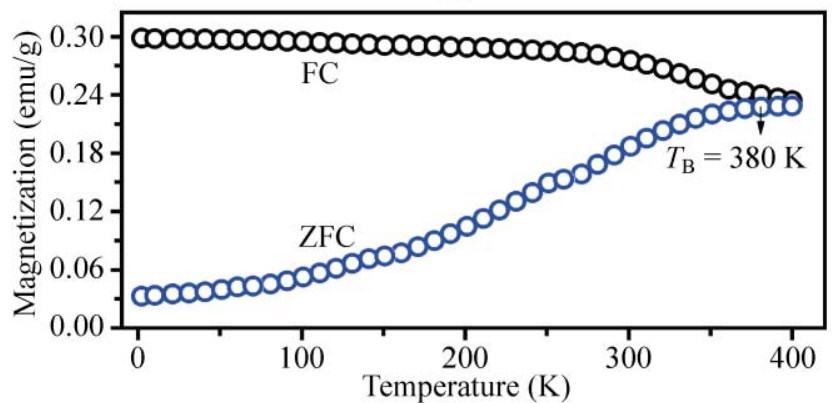

(b)

Figure 7 Temperature dependence of the magnetization of (a) NF-2-500 and (b) NF-4-500 in ZFC and FC processes. The applied magnetic field in the $\mathrm{FC}$ process was $100 \mathrm{Oe}$

nanocomposites derived from LDH precursors have $\mathrm{FM} \mathrm{NiFe}_{2} \mathrm{O}_{4}$ nanoparticles embedded in an AFM NiO matrix and exchange coupling between the spins at the interface between the FM and AFM phases leads to an additional anisotropy and a considerable increase in the $T_{\mathrm{B}}$ value (Fig. 8(b)). With increasing $\mathrm{NiO}$ concentration (Fig. 8(c)), the much stronger exchange interactions due to the larger effective AFM "thickness" around the $\mathrm{FM} \mathrm{NiFe} \mathrm{O}_{4}$ nanoparticles leads to a further increase in the blocking temperature. With a further increase in $\mathrm{NiO}$ concentration (Fig. 8(d)), however, no additional enhancement of exchange coupling between the spins at the interface between the FM and the AFM phase occurs, suggesting that the effective "thickness" of the AFM phase around the FM phase becomes saturated.

The ferromagnetic character of the calcined samples with different $\mathrm{NiFe}_{2} \mathrm{O}_{4} / \mathrm{NiO}$ ratios is evidenced by the presence of hysteresis loops when cycling the magnetic field at $10 \mathrm{~K}$ in both ZFC and FC modes in a magnetic field of $15 \mathrm{kOe}$, as shown in Fig. 9. For NF-2-500, the saturation magnetization $\left(M_{\mathrm{s}}\right)$ reached $8.10 \mathrm{emu} / \mathrm{g}$, while for NF-3-500 and NF-4-500, the magnetization does not saturate and continues to increase quasi-linearly with the field. These differences can be explained as follows: firstly, with increasing content of the $\mathrm{NiO}$ phase, which is an antiferromagent below $525 \mathrm{~K}$ [37], the shapes of the curves the dependence of magnetization $(\boldsymbol{M})$ on the field $(\boldsymbol{H})[\boldsymbol{M}(\boldsymbol{H})$ curves] are affected at high field in the composite; and secondly, the exchange bias due to the interface exchange coupling between the $\mathrm{NiFe}_{2} \mathrm{O}_{4}$ nanoparticles and the $\mathrm{NiO}$ matrix also affects the $\boldsymbol{M}(\boldsymbol{H})$ shapes at low field. The significant decrease in the value $M_{\mathrm{s}}$ with decreasing $\mathrm{NiFe}_{2} \mathrm{O}_{4}$ content can be attributed to the lower magnetic contribution as well as the poor crystallinity of the $\mathrm{NiFe}_{2} \mathrm{O}_{4}$ nanoparticles. The presence of an exchange bias also leads to a shift of the hysteresis loops relative to the field axis for the sample cooled from room temperature under an FC. The exchange bias field $\left(H_{\mathrm{E}}\right)$, is generally defined as $H_{\mathrm{E}}=-\left(H_{1}+H_{2}\right) / 2$, where $H_{1}$ and $H_{2}$ are the left and right coercive fields, respectively. Moreover, a dependence of the exchange bias field on the

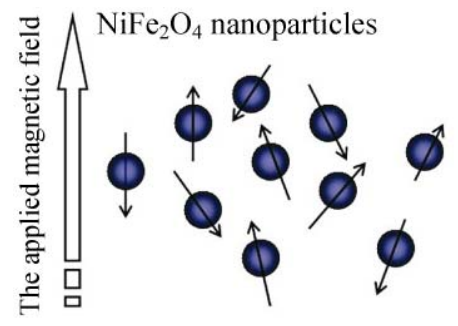

(a)

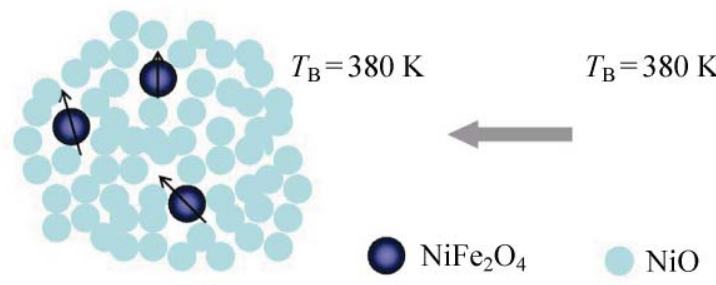

(d)
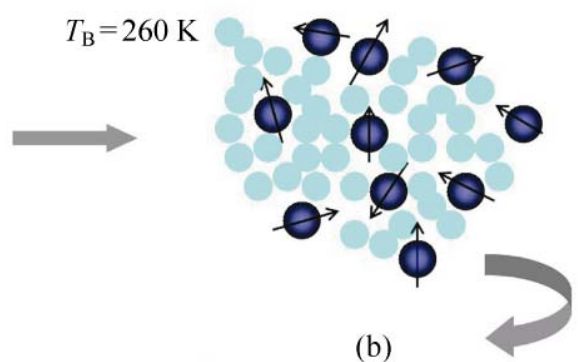

(b)

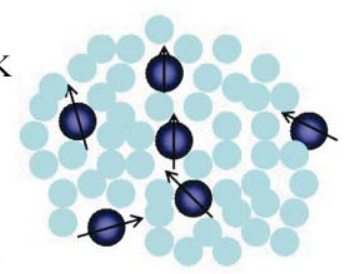

(c)

Figure 8 Schematic illustration of relationship between the $\mathrm{NiFe}_{2} \mathrm{O}_{4} / \mathrm{NiO}$ molar ratio and exchange bias effects for (a) the single-phase $\mathrm{NiFe}_{2} \mathrm{O}_{4}$ nanoparticles and the $\mathrm{NiFe}_{2} \mathrm{O}_{4} / \mathrm{NiO}$ nanocomposites derived from $\mathrm{NiFe}-\mathrm{LDHs}$ with $\mathrm{Ni} / \mathrm{Fe}$ ratios of (b) 2:1, (c) 3:1 and (d) 4:1 


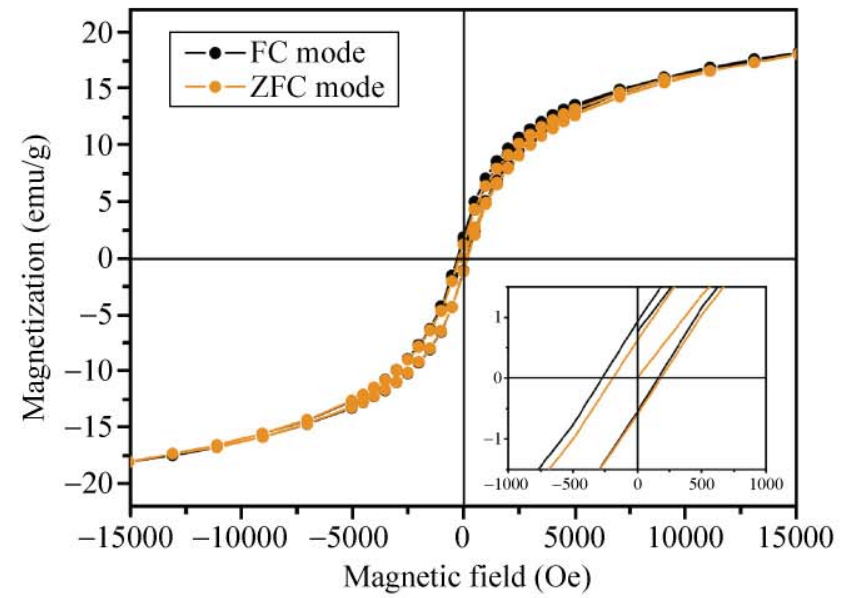

(a)

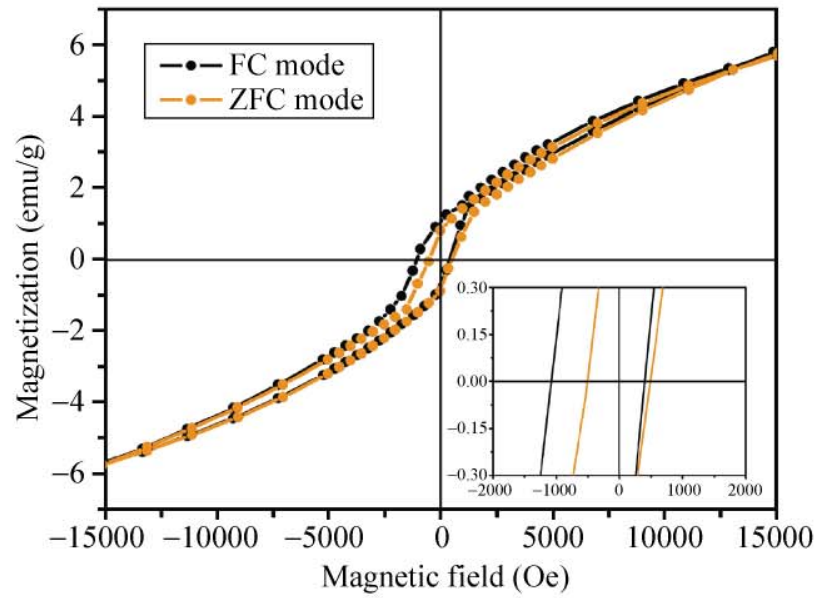

(b)

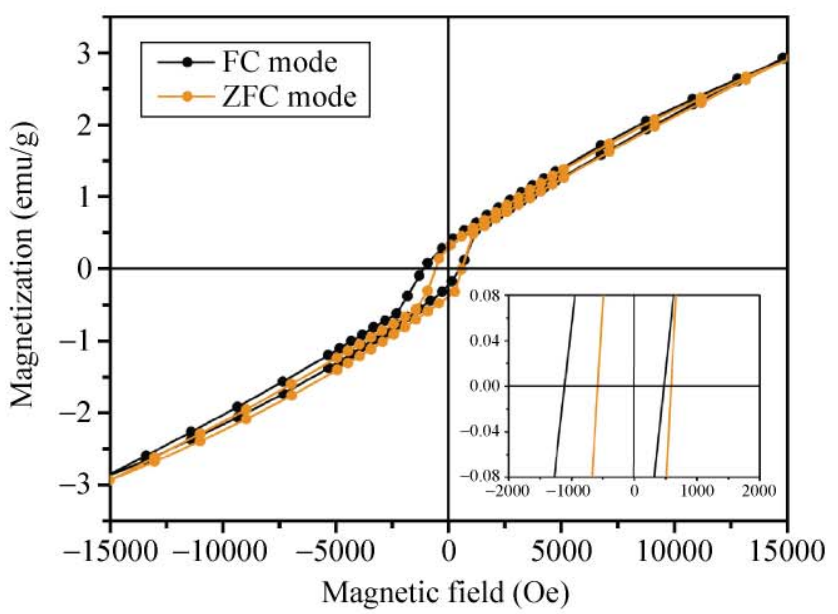

(c)

Figure 9 Hysteresis loops for the $\mathrm{NiFe}_{2} \mathrm{O}_{4} / \mathrm{NiO}$ nanocomposites (a) NF-2-500, (b) NF-3-500, and (c) NF-4-500 measured at $10 \mathrm{~K}$ for both ZFC and FC (with a magnetic field of $15 \mathrm{kOe}$ ) processes after cooling from $300 \mathrm{~K}$ to $10 \mathrm{~K}$; the insets show an enlarged view of the low field region

$\mathrm{NiFe}_{2} \mathrm{O}_{4} / \mathrm{NiO}$ ratio in the different systems also can be observed. The value of $H_{\mathrm{E}}$ increases from $53.5 \mathrm{Oe}$ to 323.5 Oe and 330.4 Oe for NF-2-500, NF-3-500 and NF-4-500, respectively.

\section{Conclusions}

We have demonstrated a facile method for beating the superparamagnetic limit of $\mathrm{NiFe}_{2} \mathrm{O}_{4}$ nanoparticles $(<10 \mathrm{~nm})$ by using composites obtained by calcining $\mathrm{NiFe}-\mathrm{LDH}$ precursors. In the high temperature treatment process, the transformation from the $\mathrm{LDH}$ precursor to the $\mathrm{NiFe}_{2} \mathrm{O}_{4} / \mathrm{NiO}$ nanocomposite occurs topotactically, and the resulting particles are clustered tightly with each other. Therefore, the value of $T_{\mathrm{B}}$ is $\sim 100 \mathrm{~K}$ higher than that of the $\mathrm{NiFe}_{2} \mathrm{O}_{4} / \mathrm{NiO}$ nanocomposite obtained by calcination of a precursor formed by a traditional chemical coprecipitation method. Meanwhile, the $\mathrm{NiFe}_{2} \mathrm{O}_{4}$ concentration in the material can also be tuned by changing the molar ratio of $\mathrm{Ni}^{\mathrm{II}} / \mathrm{Fe}^{\mathrm{II}}$ in the $\mathrm{LDH}$ precursor. The magnetic properties, such as the value of $T_{\mathrm{B}}$, as well as magnetization and the exchange field are closely related to the $\mathrm{NiFe}_{2} \mathrm{O}_{4} / \mathrm{NiO}$ ratio in the final material. Moreover, this synthesis route should be generally applicable since the wide range of metal cations which can be incorporated in LDH precursors should allow the synthesis of other FM/AFM systems. 


\section{Acknowledgements}

We would like to thank Professor David G. Evans in the State Key Laboratory of Chemical Resource Engineering, Beijing University of Chemical Technology, who helped us check the manuscript and refine the language carefully and also offered a lot of constructive suggestions for this paper. This work was supported by the National Natural Science Foundation of China, the 111 Project (No. B07004), the 973 Program (No. 2009CB939802), the Program for New Century Excellent Talents in Universities (No. NCET-07-0055), and the Beijing Nova Program (No. 2007B021).

Open Access: This article is distributed under the terms of the Creative Commons Attribution Noncommercial License which permits any noncommercial use, distribution, and reproduction in any medium, provided the original author(s) and source are credited.

\section{References}

[1] Choudhary, V. R.; Dumbre, D. K.; Uphade, B. S.; Narkhede, V. S. Solvent-free oxidation of benzyl alcohol to benzaldehyde by tert-butyl hydroperoxide using transition metal containing layered double hydroxides and/or mixed hydroxides. J. Mol. Catal. A: Chem. 2004, 215, 129-135.

[2] Casenave, S.; Martinez, H.; Guimon, C.; Auroux, A.; Hulea, V.; Cordoneanu, A.; Dumitriu, E. Acid-base properties of $\mathrm{MgNi}-\mathrm{Al}$ mixed oxides using $\mathrm{LDH}$ as precursors. Thermochim. Acta.2001, 379, 85-93.

[3] Kagunya, W.; Hassan, Z.; Jones, W. Catalytic properties of layered double hydroxides and their calcined derivatives. Inorg. Chem. 1996, 35, 5970-5974.

[4] Costantino, U.; Ambrogi, V.; Nocchetti, M.; Perioli, L. Hydrotalcite-like compounds: Versatile layered hosts of molecular anions with biological activity. Micropor. Mesopor. Mat. 2008, 107, 149-160.

[5] Williams, G. R.; O'Hare, D. Factors influencing staging during anion-exchange intercalation into $\left[\mathrm{LiAl}_{2}(\mathrm{OH})_{6}\right] \mathrm{X} \cdot m \mathrm{H}_{2} \mathrm{O}$ $\left(\mathrm{X}=\mathrm{Cl}^{-}, \mathrm{Br}^{-}, \mathrm{NO}_{3}{ }^{-}\right.$). Chem. Mater. 2005, 17, 2632-2640.

[6] Khan, A. I.; O'Hare, D. Intercalation chemistry of layered double hydroxides: Recent developments and applications. J. Mater. Chem. 2002, 12, 3191-3198.

[7] Bontchev, R. P.; Liu, S.; Kumhansl, J. L.; Vogit, J.; Nenoff, T. M. Synthesis, characterization, and ion exchange properties of hydrotalcite $\mathrm{Mg}_{6} \mathrm{Al}_{2}(\mathrm{OH})_{6}(\mathrm{~A})_{x}\left(\mathrm{~A}^{\prime}\right)_{2-x} \cdot 4 \mathrm{H}_{2} \mathrm{O}\left(\mathrm{A}, \mathrm{A}^{\prime}=\mathrm{Cl}^{-}\right.$, $\mathrm{Br}^{-}, \mathrm{I}^{-}$, and $\left.\mathrm{NO}_{3}{ }^{-}, 2 \geqslant x \geqslant 0\right)$ derivatives. Chem. Mater. 2003, 15, 3669-3675.

[8] Pavan, P. C.; Gomes, G.; Valim, J. B. Adsorption of sodium dodecyl sulfate on layered double hydroxides. Micropor. Mesopor. Mat. 1998, 21, 659-665.

[9] Lv, L.; He, J.; Wei, M.; Evans, D. G.; Duan, X. Uptake of chloride ion from aqueous solution by calcined layered double hydroxides: Equilibrium and kinetic studies. Water Res. 2006, 40, 735-743.

[10] Combourieu, B.; Inacio, J.; A. Delort, M.; Forano, C. Differentiation of mobile and immobile pesticides on anionic clays by ${ }^{1}$ H HR MAS NMR spectroscopy. Chem. Commun. 2001, 2214-2215.

[11] Desigaux, L.; Belkacem, M. B.; Richard, P.; Cellier, J.; Léone, P.; Cario, L.; Leroux, F.; Taviot-Guého, C.; Pitard, B. Self-assembly and characterization of layered double hydroxide/DNA hybrids. Nano Lett. 2006, 6, 199-204.

[12] Darder, M.; López-Blanco, M.; Aranda, P.; Leroux, F.; Ruiz-Hitzky, E. Bio-nanocomposites based on layered double hydroxides. Chem. Mater. 2005, 17, 1969-1977.

[13] Yuan, Q.; Wei, M.; Evans, D. G.; Duan, X. Preparation and investigation of thermolysis of $L$-aspartic acid-intercalated layered double hydroxide. J. Phys. Chem. B 2004, 108, 12381-12387.

[14] Ren, L.; He, J.; Zhang, S.; Evans, D. G.; Duan, X. Immobilization of penicillin $\mathrm{G}$ acylase in layered hydroxides pillared by glutamate ions. J. Mol. Catal. B: Enzym. 2002, 18, 3-11.

[15] Carriazo, D.; Domingo, C.; Martin C.; Rives, V. Structural and texture evolution with temperature of layered double hydroxides intercalated with paramolybdate anions. Inorg. Chem. 2006, 45, 1243-1251.

[16] Morandi, S.; Prinetto, F.; Martino, M. D.; Ghiotti, G.; Lorret, O.; Tichit, D.; Malagù, C.; Vendemiati B.; Carotta, M. C. Synthesis and characterization of gas sensor materials obtained from $\mathrm{Pt} / \mathrm{Zn} / \mathrm{Al}$ layered double hydroxides. Sensor. Actuat. B-Chem. 2006, 118, 215-220.

[17] Liu, J. P.; Li, Y. Y.; Huang, X. T.; Li, G. Y.; Li, Z. K. Layered double hydroxide nano- and microstructures grown directly on metal substrates and their calcined products for application as Li-ion battery electrodes. Adv. Funct. Mater. 2008, 18, 1448-1458.

[18] Li, F.; Liu, J. J.; Evans, D. G.; Duan. X. Stoichiometric synthesis of pure $\mathrm{MFe}_{2} \mathrm{O}_{4}(\mathrm{M}=\mathrm{Mg}, \mathrm{Co}$, and Ni) spinel ferrites from tailored layered double hydroxide (hydrotalcite-like) precursors. Chem. Mater. 2004, 16, 1597-1602.

[19] Sideris, P. J.; Nielsen, U. G.; Gan, Z. H.; Grey, C. P. Mg/Al ordering in layered double hydroxides revealed by multinuclear NMR spectroscopy. Science 2008, 321, 113-117.

[20] Li, C.; Wang, L. Y.; Wei, M.; Evans, D. G.; Duan, X. Large oriented mesoporous self-supporting $\mathrm{Ni}-\mathrm{Al}$ oxide films derived from layered double hydroxide precursors. J. Mater. Chem. 2008, 18, 2666-2672. 
[21] Millange, F; Walton, R. I.; O'Hare, D. Time-resolved in situ $\mathrm{X}$-ray diffraction study of the liquid-phase reconstruction of $\mathrm{Mg}-\mathrm{Al}$-carbonate hydrotalcite-like componds. J. Mater. Chem. 2000, 10, 1713-1720.

[22] Del Arco, M.; Malet, P.; Trujillano, R.; Rives, V. Synthesis and characterization of hydrotalcites containing $\mathrm{Ni}$ (II ) and $\mathrm{Fe}(\mathrm{III})$ and their calcination products. Chem. Mater. 1999, 11, 624-633.

[23] Rondinone, A. J.; Samia, A. C. S.; Zhang Z. J. Superparamagnetic relaxation and magnetic anisotropy energy distribution in $\mathrm{CoFe}_{2} \mathrm{O}_{4}$ spinel ferrite nanocrystallites. J. Phys. Chem. B 1999, 103, 6876-6880.

[24] Cheng, Z. J; Lin, L.; Jiang, L. Tunable adhesive superhydrophobic surfaces for superparamagnetic microdroplets. Adv. Funct. Mater. 2008, 18, 1-7.

[25] Sun, S. H.; Murray, C. B.; Weller, D.; Folks, L.; Moser, A. Monodisperse FePt nanoparticles and ferromagnetic FePt nanocrystal superlattices. Science 2000, 287, 1989-1992.

[26] Lüders, U.; Barthélémy, A.; Bibes, M.; Bouzehouane, K.; Fusil, S.; Jacquet, E.; Contour, J. -P.; Bobo, J. -F.; Fontcuberta, J.; Fert, A. $\mathrm{NiFe}_{2} \mathrm{O}_{4}$ : A versatile spinel material brings new opportunities for spintronics. Adv. Mater. 2006, 18, 1733-1736.

[27] Martín, J. I.; Nogués, J.; Liu, K.; Vicent, J. L.; Schuller, I. K. Ordered magnetic nanostructures: Fabrication and properties. J. Magn. Magn. Mater. 2003, 256, 449-501.

[28] Kodama, R. H. Magnetic nanoparticles. J. Magn. Magn. Mater. 1999, 200, 359-372.

[29] Kremenovic, A.; Antic, B.; Spasojevic, V.; Vucinic-Vasic, M.; Jaglicic, Z.; Pirnat, J.; Trontelj, Z. X-ray powder diffraction line broadening analysis and magnetism of interacting ferrite nanoparticles obtained from acetylacetonato complexes. J. Phys.: Condens. Matter 2005, 17, 4285-4299.

[30] Vestal, C. R.; Song, Q.; Zhang, Z. J. Effects of interparticle interactions upon the magnetic properties of $\mathrm{CoFe}_{2} \mathrm{O}_{4}$ and $\mathrm{MnFe}_{2} \mathrm{O}_{4}$ nanocrystals. J. Phys. Chem. B 2004, 108, 18222-18227.

[31] Skumryev, V.; Stoyanov, S.; Zhang, Y.; Hadjipanayis, G.; Givord, D.; Nogués, N. Beating the superparamagnetic limit with exchange bias. Nature 2003, 423, 850-853.

[32] Lee, I. S.; Lee, N.; Park, J.; Kim, B. H.; Yi, Y. -W.; Kim, T.; Kim, T. K.; Lee, I. H.; Paik, S. R.; Hyeon, T. Ni/NiO core/shell nanoparticles for selective binding and magnetic separation of histidine-tagged proteins. J. Am. Chem. Soc. 2006, 128, 10858-10859.

[33] Redl, F. X.; Black, C. T.; Papaefthymiou, G. C.; Sandstrom, R. L.; Yin, M.; Zheng, H.; Murria, C. B.; Brien, S. P. Magnetic, electronic, and structural characterization of nonstoichiometric iron oxides at the nanoscale. J. Am. Chem.
Soc. 2004, 126, 14583-14599.

[34] Salazar-Alvarez, G.; Sort, J.; Surinach, S.; Baro, M. D.; Nogués, J. Synthesis and size-dependent exchange bias in inverted core-shell $\mathrm{MnO} \mid \mathrm{MnO}$ nanoparticles. J. Am. Chem. Soc. 2007, 129, 9102-9108.

[35] Nogués, J. H.; Sort, J.; Langlais, V.; Doppiu, S.; Dieny, B.; Munoz, J. S.; Surinach, S.; Baro, M. D.; Stoyanov, S.; Zhang, Y. Exchange bias in ferromagnetic nanoparticles embedded in an antiferromagnetic matrix. Int. J. Nanotechnol. 2005, 2, 23-42.

[36] Masala, O.; Seshadri, R. Spinel ferrite/MnO core/shell nanoparticles: Chemical synthesis of all-oxide exchange biased architectures. J. Am. Chem. Soc. 2005, 127, 9354-9355.

[37] Artus, M.; Ammar, S.; Sicard, L.; Piquemal, J. -Y.; Herbst, F.; Vaulay, M. -J.; Fiévet, F.; Richard, V. Synthesis and magnetic properties of ferrimagnetic $\mathrm{CoFe}_{2} \mathrm{O}_{4}$ nanoparticles embedded in an antiferromagnetic $\mathrm{NiO}$ matrix. Chem. Mater. 2008, 20, 4861-4872.

[38] Tian, Z. M.; Yuan, S. L.; Yin, S. Y.; Liu, L.; He, J. H.; Duan, H. N.; Li, P.; Wang, C. H. Exchange bias effect in a granular system of $\mathrm{NiFe}_{2} \mathrm{O}_{4}$ nanoparticles embedded in an antiferromagnetic NiO matrix. Appl. Phys. Lett. 2008, 93, 222505.

[39] Zhao, Y.; Li, F.; Zhang, R.; Evans, D. G.; Duan, X. Preparation of layered double-hydroxide nanomaterials with a uniform crystallite size using a new method involving separate nucleation and aging steps. Chem. Mater. 2002, 14, 4286-4291.

[40] Rebours, B.; d'Espinose de la Caillerie, J. -B.; Clause, O. Decoration of nickel and magnesium oxide crystallites with spinel-type phases. J. Am. Chem. Soc. 1994, 116, 1707-1717.

[41] Pettigrew, K. A.; Long, J. W.; Carpenter, E. E.; Baker, C. C.; Lytle, J. C.; Chervin, C. N.; Logan, M. S.; Stroud, R. M.; Rolison. D. R. Nickel ferrite aerogels with monodisperse nanoscale building blocks-The importance of processing temperature and atmosphere. ACS Nano 2008, 2, 784-790.

[42] Šepelák, V.; Bergmann, I.; Feldhoff, A.; Heitjans, P.; Krumeich, F.; Menzel, D.; Litterst, F. J.; Campbell, S. J.; Becker, K. D. Nanocrystalline nickel ferrite, $\mathrm{NiFe}_{2} \mathrm{O}_{4}$ : Mechanosynthesis, nonequilibrium cation distribution, canted spin arrangement, and magnetic behavior. J. Phys. Chem. C 2007, 111, 5026-5033.

[43] Jensen, P. J. Magnetic recording medium with improved temporal stability. Appl. Phys. Lett. 2001, 78, 2190-2192.

[44] Luo, W.; Nagel, S. R.; Rosenbaum, T. F.; Rosensweig, R. E. Dipole interactions with random anisotropy in a frozen ferrofluid. Phys. Rev. Lett. 1991, 67, 2721-2724.

[45] Maniya, H.; Nakatani, L.; Furubayashi, T. Blocking and freezing of magnetic moments for iron nitride fine particle systems. Phys. Rev. Lett. 1997, 80, 177-180. 